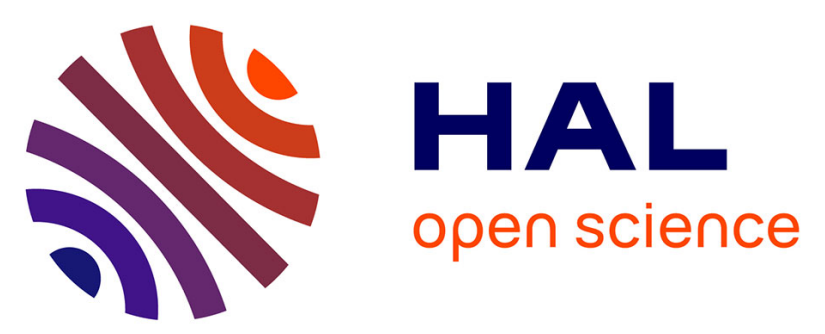

\title{
Dissociative Photodetachment vs. Photodissociation of Aromatic Carboxylates: The Benzoate and Naphthoate Anions
}

Gustavo Ariel Pino, Rafael A Jara-Toro, Juan P Aranguren-Abrate, Claude Dedonder-Lardeux, Christophe Jouvet

\section{To cite this version:}

Gustavo Ariel Pino, Rafael A Jara-Toro, Juan P Aranguren-Abrate, Claude Dedonder-Lardeux, Christophe Jouvet. Dissociative Photodetachment vs. Photodissociation of Aromatic Carboxylates: The Benzoate and Naphthoate Anions. Physical Chemistry Chemical Physics, 2019, 21 (4), pp.17971804. 10.1039/c8cp07162d. hal-02111704

\section{HAL Id: hal-02111704 https://hal-amu.archives-ouvertes.fr/hal-02111704}

Submitted on 26 Apr 2019

HAL is a multi-disciplinary open access archive for the deposit and dissemination of scientific research documents, whether they are published or not. The documents may come from teaching and research institutions in France or abroad, or from public or private research centers.
L'archive ouverte pluridisciplinaire HAL, est destinée au dépôt et à la diffusion de documents scientifiques de niveau recherche, publiés ou non, émanant des établissements d'enseignement et de recherche français ou étrangers, des laboratoires publics ou privés. 


\section{Dissociative Photodetachment vs. Photodissociation of Aromatic Carboxylates: The Benzoate and Naphthoate Anions}

Gustavo A. Pino, ${ }^{b, c, d, *}$ Rafael A. Jara-Toro, ${ }^{b, c, d}$ Juan P. Aranguren-Abrate, ${ }^{a}$ Claude Dedonder-Lardeux ${ }^{\mathrm{a}}$ and Christophe Jouvet ${ }^{\mathrm{a}}$

a- Physique des Interactions loniques et Moléculaires (PIIM): UMR-CNRS 7345 Aix-Marseille Université, Avenue Escadrille Normandie-Niémen, 13397 Marseille Cedex 20, France.

b- INFIQC: Instituto de Investigaciones en Fisicoquímica de Córdoba (CONICET - UNC) - Haya de la Torre y Medina Allende, Ciudad Universitaria, X5000HUA Córdoba, Argentina.

c- Departamento de Fisicoquímica, Facultad de Ciencias Químicas Universidad Nacional de Córdoba - Haya de la Torre y Medina Allende, Ciudad Universitaria, X5000HUA Córdoba, Argentina.

d- Centro Láser de Ciencias Moleculares - Universidad Nacional de Córdoba Haya de la Torre s/n, Pabellón Argentina, Ciudad Universitaria, X5000HUA Córdoba, Argentina.

*Corresponding author: gpino@fcq.unc.edu.ar 


\begin{abstract}
The competition between dissociative photodetachment and photodissociation of cold benzoate and naphthoate anions was studied through measurement of the kinetic energy of the neutral fragments and intact parent benzoyloxy and naphtoyloxy radicals as well as by detecting the anionic fragments whenever they are produced. For the benzoate anion, there is no ionic photodissociation and the radical dissociation occurs near the vertical photodetachment energy. This is in agreement with DFT calculations showing that the dissociation energy in $\mathrm{CO}_{2}$ and $\mathrm{C}_{6} \mathrm{H}_{5}{ }^{\circ}$ is very low. The dissociation barrier can be deduced from experimental results and calculations to be $(0.7 \pm$ $0.10) \mathrm{eV}$, which makes the benzoyloxyradical $\mathrm{C}_{6} \mathrm{H}_{5} \mathrm{COO} \mathrm{O}^{\bullet}$ very unstable, although more stable than the acetyloxy radical. In the case of naphthoate, the observation of negative fragments at low excitation energies demonstrates the opening of the ionic photodissociation channel in the excited state of the naphthoate anion, whose yield decreases at higher energies when the dissociative photodetachment channel opens.
\end{abstract}




\section{Introduction}

The alky/aryl carboxylate anions are the conjugated bases of the corresponding organic acids. These acids are very important in organic chemistry since they serve as reactants for many reactions. The photodecarboxylation of the anions is often used to produce the corresponding alkyl/aryl radical. As a first general approach, it is suggested that the primary process is the photodetachment to produce the corresponding alkyloxy/aryloxy radical internally hot, followed by the elimination of the $\mathrm{CO}_{2}$ molecule, giving rise to the dissociative photodetachment.

Dissociative photodetachment (DPD) is a process that has been observed for many small molecular systems ${ }^{1}$ and recent progresses on this topic can be found in a review by Continetti et al. ${ }^{2}$ For the acetyl carboxylate anion $\mathrm{CH}_{3} \mathrm{CO}_{2}^{-}$the DPD has been studied by coincidence experiments and both the unbroken acetyloxy radical and its fragments have been observed implying the presence of a barrier in the exit channel for the dissociation into $\mathrm{CO}_{2}+\mathrm{CH}_{3}{ }^{3}$ This barrier has been calculated ${ }^{4}$ to be around $0.2 \mathrm{eV}$.

Interestingly, in the case of the aryl carboxylate anions, if an optically active excited state is lower in energy than the Adiabatic Detachment Energy $(A D E)$, the photodissociation of the anion can compete with the DPD as observed for the green fluorescent protein chromophore ( $p$-hydroxybenzylidene2,3-dimethylimidazolone). ${ }^{5-7}$ For aromatic molecules, it is well known that the excited states shift to lower energies as the size of the aromatic ring increases, and thus it is possible to change the position of the excited states of the anion by changing the size of the aromatic moieties. In the case of the smallest aryl carboxylates, one can go from the situation where the excited state is higher than the $A D E$ to the inverse one, which would allow studying the competition between photodetachment and anionic photodissociation.

Although benzoate $\left(\mathrm{BzCO}_{2}{ }^{-}\right)$and naphthoate $\left(\mathrm{NpCO}_{2}^{-}\right)$are the simplest aromatic carboxylate anions, there are not so many detailed studies at the molecular level that allow understanding their properties (excited states dynamics, stability, etc.) and those of their corresponding benzoyloxy $\left(\mathrm{BzCO}_{2}{ }^{\circ}\right)$ and naphtoyloxy $\left(\mathrm{NpCO}_{2}{ }^{\circ}\right)$ neutral radicals. 
The benzoate anion has been well characterized by its photoelectron spectrum ${ }^{8}$ at low temperature. The onset of the electron binding energy is quite ill-defined, which prevents a clear determination of the ADE of the benzoate anion. An experimental value is estimated to be $(3.59 \pm 0.16) \mathrm{eV}$. The benzoate anion vibrational spectroscopy has been characterized by infrared multi photon electron detachment and the ADE has been calculated with different methods to be in the range $(3.33-3.44) \mathrm{eV}^{9}$

As far as we know, there are no experimental data for naphthoate and only a low resolution electronic spectrum of neutral naphthoic acid is known, ${ }^{10}$ from which the origin of the $S_{1} \leftarrow S_{0}$ transition has been determined to be at around $335 \mathrm{~nm}$ as expected for naphthalene derivatives.

From the methodological point of view, the study of DPD requires either the detection of the electron or the detection of neutral fragments, which is not so easy to achieve in experimental setups built to detect ions with a MCP detector (Multi Channel Plates). One way to detect neutrals on such a detector is to accelerate the parent ions to a few $\mathrm{keV}$ before fragmentation, the fragments will then keep the kinetic energy of the parent ions allowing their detection. ${ }^{11-13}$ This technique is very often used in coincidence experiments by detecting the energy resolved electron and the neutral ${ }^{2,14-16}$ or the ionic and neutral fragments when fragmentation occurs instead of photodetachment. ${ }^{17}$ Two kinds of information can be obtained from this type of experiments: the fragmentation efficiency when the energy in the system can be varied or determined (photoelectron neutral coincidence) or the kinetic energy of the fragments.

The measurement of the dissociation threshold requires the control of the internal energy of the neutral after the electron ejection. This can be achieved either by coincidence experiments or by varying the photon energy and having the knowledge of the electron binding energy ${ }^{8}$ which allows to know the internal energy distribution. In order to increase the accuracy of the measurement it is useful to control the temperature of the ion by using cold ions.

In this line, and with the goal of studying the competition between DPD and anionic photofragmentation, we present here experimental results on the photoinduced fragmentation processes of cold benzoate and naphthoate anions obtained by measuring the variation of the kinetic energy of the neutral 
fragments as a function of the photon energy, as well as the presence of the neutral aryloxy parent radical and the corresponding anionic fragments, when they are present. The experimental results are complemented by DFT calculations to help their interpretation.

\section{Methodology}

\section{Experimental}

Benzoate $\left(\mathrm{BzCO}_{2}^{-}\right)$and 2-naphthoate anions $\left(\mathrm{NpCO}_{2}^{-}\right)$were produced in the ESI source by injecting a solution of benzoic or 2-naphthoic acid $10^{-4} \mathrm{M}$ in 1:1 mixture of methanol:water.

The experimental setup for cold ions photofragmentation spectroscopy has been already described in previous publications. ${ }^{18-20}$

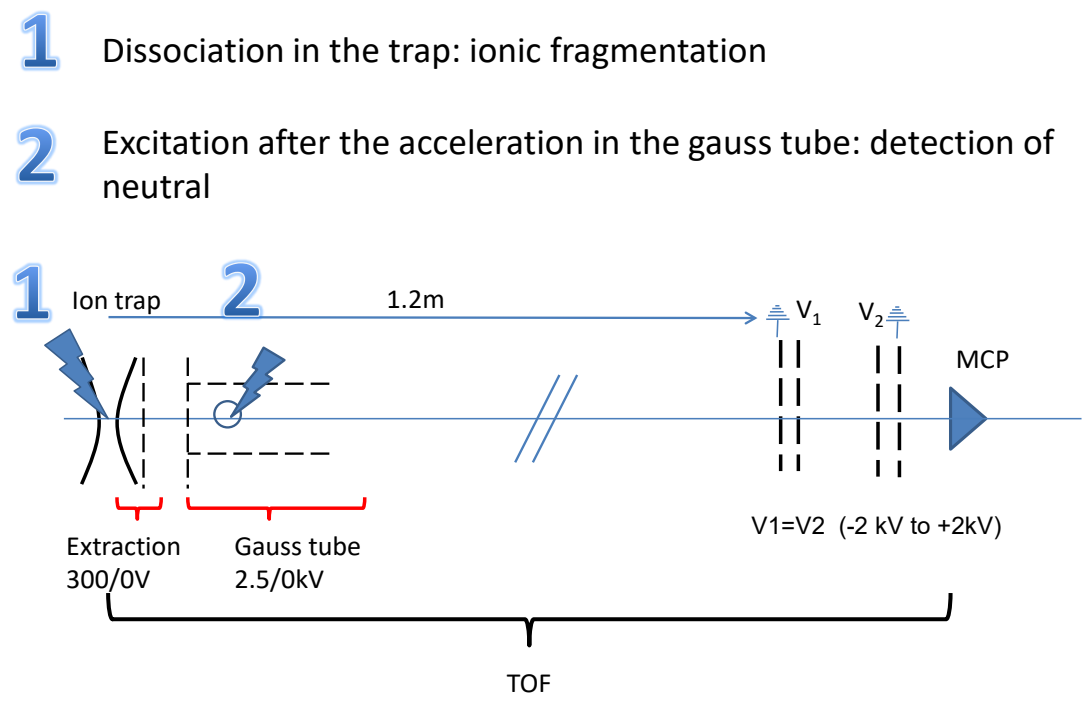

Figure 1: Scheme of the experimental setup. The two regions where the laser interacts with the ion packet are represented.1) in the cold trap, 2) in the gauss tube.

In this work, the experimental setup was modified to detect negative ions and neutral particles and only the details of these modifications are reported here. Briefly, the ions produced by the electrospray source (ESI) are injected in the ion trap just after the helium pulse has been sent in. They are stored in the cold trap for $80 \mathrm{~ms}$, the time necessary for the cooling up to $30 \mathrm{~K}^{21}$ and the decrease of the pressure in the trap. The ions are then extracted and accelerated at $2.6 \mathrm{kV}$. The voltage of the extracting electrode of the trap and the accelerating grid are adjusted in order to fulfill the Wiley McLaren focusing 
conditions. ${ }^{22}$ After the accelerating grid, the ions enter in the Gauss tube whose function is to avoid having everything floating. Once the ions are inside the tube, it is set at the accelerating grid potential and it is switched to ground before the ions exit the tube. The ions then travel in the field free region of the time of flight (TOF) mass spectrometer with a kinetic energy due to the accelerating voltage and they are referenced to the ground. After $1 \mathrm{~m}$ of flight, they enter the post accelerating/decelerating "box". The ions or the neutrals are detected after the "box" with a MCP detector mounted in the positive detection mode, which avoids the destruction of the subsequent electronics in case of current failure (since the kinetic energy of the negative ions is much larger than the voltage on the first MCP, the ions are detected efficiently).

The laser can interact with the ions in two different parts of the setup:

1) In the ion trap: this allows monitoring the photodissociation process leading to a daughter ion and a neutral fragment by extracting the ions after the laser shot.

2) In the Gauss tube: since the parent ions are accelerated, the neutral parent radicals produced after the photodetachment or the neutral daughter fragments can be detected by the MCP. The intact parent radical will arrive at the same time as the anion precursor and the signal will be as narrow as the anion signal. In contrast, the neutral fragments will travel with the kinetic energy of the parent ion plus the kinetic energy released in the dissociative process. They will be observed at the same time-offlight as the parent but with a peak broadening due to kinetic energy release.

To discriminate between the parent anion and the parent neutral photodetached radical, three methods can be used:

a) Placing deflection plates perpendicular to the ion travel direction to prevent the anions to reach the detector.

b) Accelerating or decelerating the anions by applying high voltages $(1.2 \mathrm{kV})$ in the post accelerating/decelerating box (eg. if a negative voltage is applied, the ions are decelerated in the box and will travel slower than the neutral in the box and then will arrive after the neutrals to the detector). 
c) Leaving the voltage on the Gauss tube in order to decelerate the anions at the output of the tube and prevent them to reach the detector whereas the neutral are not perturbed. This method minimizes the time and the distance travelled by the ions and thus minimizes the background signal due to neutral molecules produced by collisions of the parent ion with the residual gas.

Photodissociation of the ions was achieved with a tunable OPO laser (EKSPLA) $(10 \mathrm{~Hz}$ repetition rate, $10 \mathrm{~ns}$ pulse width and a spectral resolution of $\sim 10 \mathrm{~cm}^{-1}$ ). The linear polarization of the laser was perpendicular to the ion path and no changes in the neutrals profiles were observed when the linear polarization of the laser was set parallel to the ion path.

\section{Calculations}

Simple calculations using the density functional theory (DFT) with the B3LYP functional as implemented in the Turbomolesoftware, ${ }^{23}$ with basis sets up to cc-pVTZ ${ }^{24}$ were performed in order to determine theAdiabatic and Vertical Detachment Energies (ADE and VDE, respectively) as well as the dissociation energy and the $S_{n} \leftarrow S_{0}$ adiabatic transition energy of the anions $\left(E_{a d}\right)$.

The Intrinsic Reaction Coordinate (IRC) or Minimum Energy Path (MEP) and excited state calculations for the decomposition of the $\mathrm{BzCO}_{2}{ }^{\bullet}$ and $\mathrm{NpCO}_{2}{ }^{\bullet}$ radicals were performed with the CAM-B3LYPfunctional and the cc-pVDZ basis set with the Gaussian 09 suite of programs. ${ }^{25}$

\section{Results}

\section{Benzoate $\left(\mathrm{BzCO}_{2}^{-}\right)$:}

At first we tried to observe photodissociation of the benzoate anion $\mathrm{BzCO}_{2}{ }^{-}$sending the laser in the ion trap (region 1 of Figure 1) as was done for protonated species, but no ionic fragments were observed indicating the absence of the photodissociation channel over the photon energy range probed in this work $(3.2-5.4) \mathrm{eV}$.

The photodetachement of $\mathrm{BzCO}_{2}^{-}$and/or the radical fragmentation were performed in the Gauss tube (region 2 of Figure 1 ) by leaving the voltage in the tube in order to prevent the parent anions to reach the detector and minimizing 
the background signal due to neutrals produced by collision induced dissociation.

The symmetrized TOF profiles of the neutrals fragments produced by interaction of the laser with $\mathrm{BzCO}_{2}^{-}$at different photon energies are shown in Figure 2. A symmetrization procedure is necessary due to imperfections in the MCP electronic circuit that induces a deformation on the high time part of the TOF profiles and is explained in the S.I. (Figure SI-1).

The TOF profiles of the neutral species are composed of two kinds of peaks: a narrow one which has the width of the parent signal (i.e. 20 ns) and a broad peak with a width of a few hundreds of nanoseconds. The narrow peak corresponds to the intact neutral benzoyloxy $\left(\mathrm{BzCO}_{2}{ }^{\circ}\right)$ radical produced as a consequence of the photodetachment process and the broad one to neutral $\mathrm{CO}_{2}$ and $\mathrm{C}_{6} \mathrm{H}_{5}{ }^{\bullet}$ (phenyl radical) fragments.
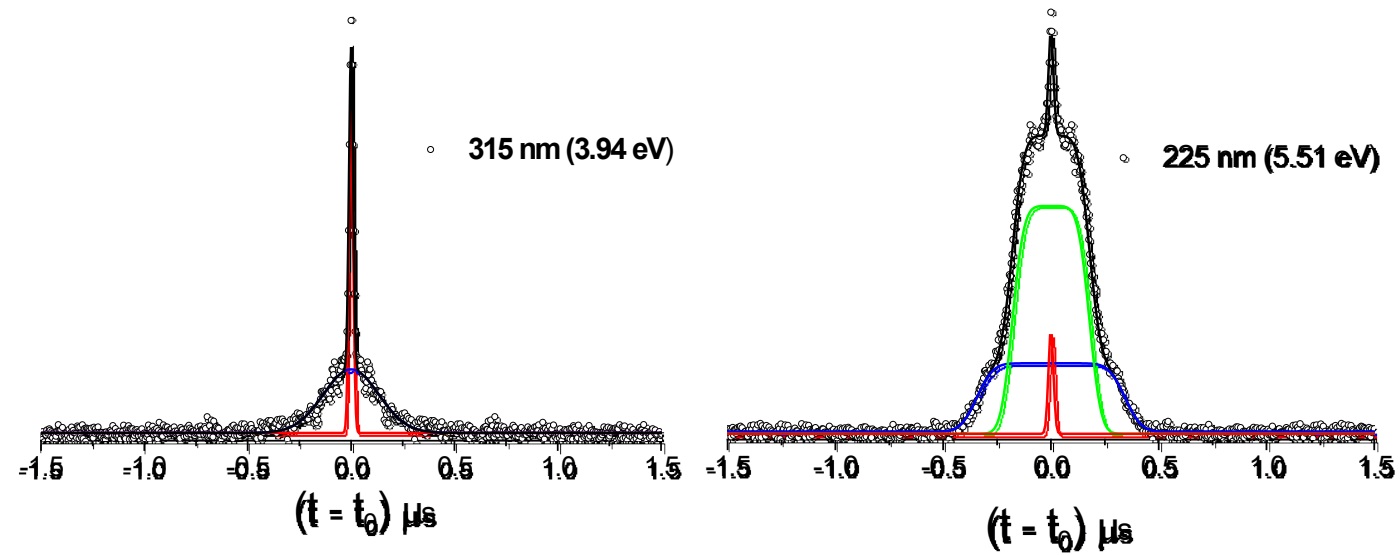

Figure 2: TOF profiles of the neutrals generated from the interaction of the laser with cold $\mathrm{BzCO}_{2}{ }^{-}$anions (40K) in the Gauss tube at different photon energies. Left: laser at $315 \mathrm{~nm}(3.94 \mathrm{eV})$ and right: laser at 225nm (5.50 eV). (o) Experimental profile, ( $\longrightarrow$ ) Gaussian function corresponding to intact $\mathrm{NpCO}_{2}{ }^{\circ}$ radical, (-) step-function corresponding to $\mathrm{Np}^{\bullet}$ radical, (-) step-function corresponding to $\mathrm{CO}_{2}$ and (-) total fitting. The experimental peaks were symmetrized according to the procedure described in the S.I.

The TOF profiles are strongly dependent on the photon energy: the intensity of the narrow peak associated to $\mathrm{BzCO}_{2}{ }^{\bullet}$ is present at all the excitation energies explored and continuously decreases with increasing photon energy, while the broad component increases with the photon energy. This is interpreted as follows: the primary process is the photodetachment to produce internally excited $\mathrm{BzCO}_{2}{ }^{\bullet}$ radical. As the photon energy increases also does the 
fraction of $\mathrm{BzCO}_{2}{ }^{\bullet}$ radicals with internal energy above the energy barrier for dissociation to $\mathrm{CO}_{2}$ and $\mathrm{C}_{6} \mathrm{H}_{5}{ }^{\circ}$ and as a consequence the broad component associated to these fragments also increases while the narrow peak decreases.

The fitting was then performed as the sum of a narrow Gaussian function (accounting for the $\mathrm{BzCO}_{2}{ }^{\bullet}$ component) and two step-functions (accounting for $\mathrm{CO}_{2}$ and $\mathrm{Bz}^{\bullet}$ fragments) with variable widths and slopes.

The fragmentation yield shown in Figure 3 as a function of the photon energy is given by $\left(A_{\text {broad }} / 2\right) /\left(A_{\text {narrow }}+A_{\text {broad }} / 2\right)$, where $A_{\text {broad }}$ is the total integral of the two broad step functions corresponding to the recoiling $\mathrm{CO}_{2}$ and $\mathrm{C}_{6} \mathrm{H}_{5}{ }^{\circ}$ fragments and $A_{\text {narrow }}$ is the integral of the narrow one representing the intact $\mathrm{BzCO}_{2}{ }^{\bullet}$ radical. The factor $1 / 2$ for the broad component takes into account that there are 2 fragments. As show in Figure 3, even at the lowest energy $(3.88 \mathrm{eV})$ the fragmentation yield is quite high $(45 \pm 10) \%$, reaching $90 \%$ of dissociation at $4.5 \mathrm{eV}$.

From the width of the step function, the relative kinetic energy of the fragments was $(0.32 \pm 0.04) \mathrm{eV}$ at $5.39 \mathrm{eV}(230 \mathrm{~nm})$ of excitation energy.

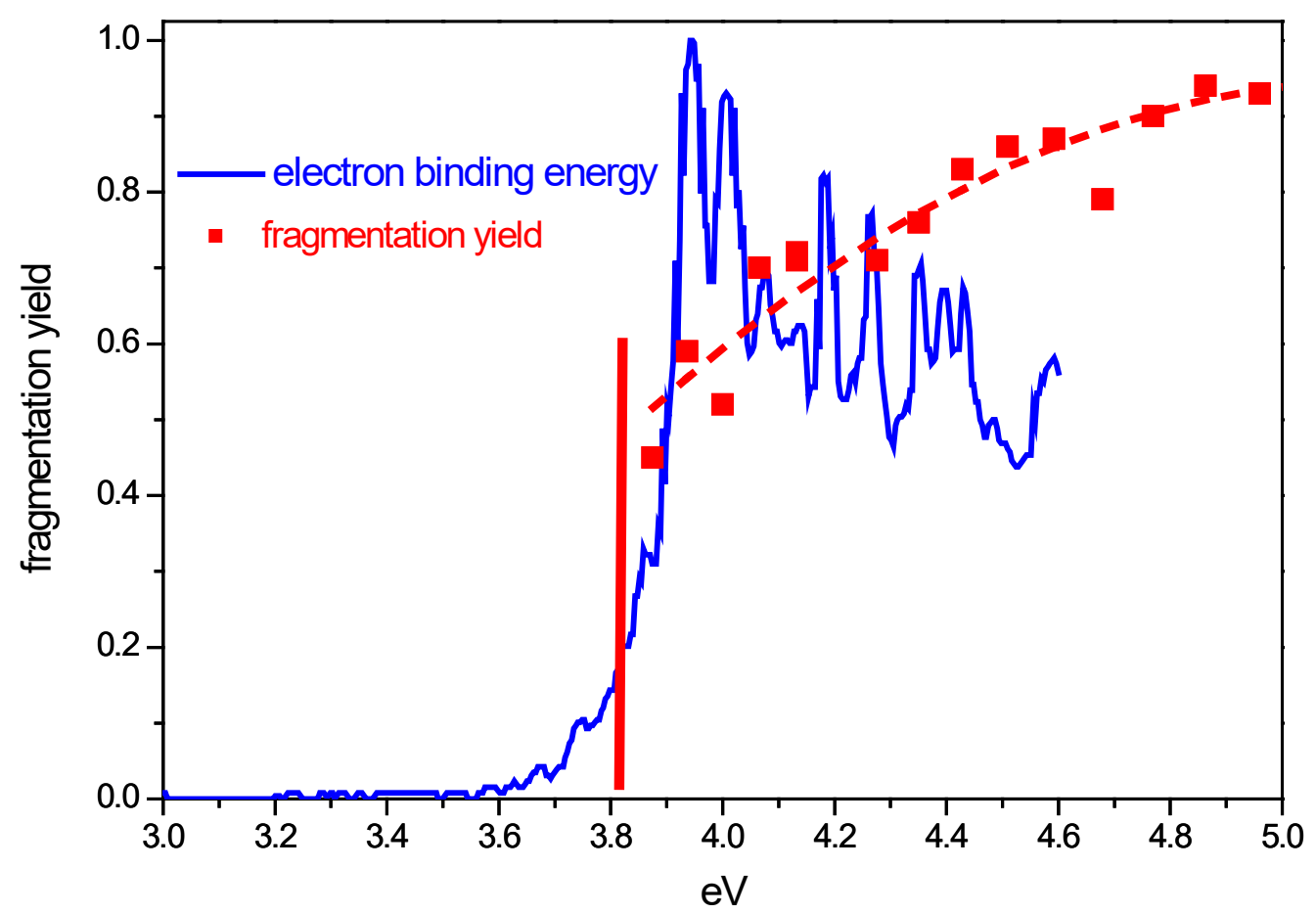

Figure 3: Fragmentation yield of the $\mathrm{BzCO}_{2}{ }^{\circ}$ radical as a function of the photon energy (red squares and broken line). In blue the electron binding energy obtained at 18K adapted from Woo et al. ${ }^{8}$ The vertical red line is the estimated fragmentation threshold (see discussion section). 


\section{Naphthoate $\left(\mathrm{NpCO}_{2}{ }^{-}\right)$:}

Unlike $\mathrm{BzCO}_{2}^{-}$, the interaction of $\mathrm{NpCO}_{2}^{-}$with the laser in the ion-trap (region 1) leads to the production of a daughter anion of $\mathrm{m} / \mathrm{z}=127$ assigned to the $\mathrm{C}_{10} \mathrm{H}_{7}^{-}$anion $\left(\mathrm{Np}^{-}\right)$, its counter fragment being $\mathrm{CO}_{2}$ as explained below. The dependence of the intensity of the $\mathrm{Np}^{-}$fragment on the excitation wavelength, depicted in Figure 4, shows a threshold for the photodissociation below $3.4 \pm$ $0.2 \mathrm{eV}(360 \mathrm{~nm})$, a maximum signal around $4.2 \mathrm{eV}$ and the fragment signal vanishes at energies above $4.8 \pm 0.2 \mathrm{eV}(258 \mathrm{~nm})$.

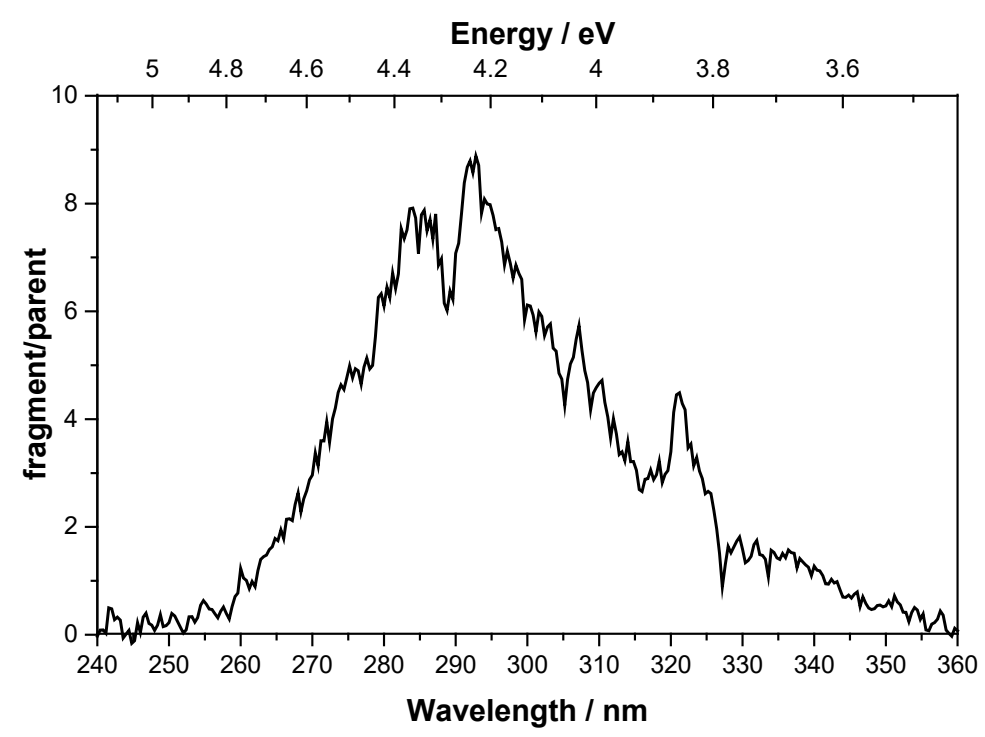

Figure 4: Action spectrum of the $\mathrm{NpCO}_{2}^{-}$anion recorded on the mass of the $\mathrm{Np}^{-}$anion. The only reproducible feature in this spectrum is the broad band at $321 \mathrm{~nm}$. The absence of narrow bands implies a very fast non radiative process in the excited state of the parent anion.

The photodetachment of $\mathrm{NpCO}_{2}{ }^{-}$and DPD processes in the Gauss tube lead to more complex results than in the case of $\mathrm{BzCO}_{2}^{-}$. Figure 5 shows typical TOF profiles at different excitation wavelengths and three different regimes are observed:

1) Low excitation energies $(3.25-3.75 \mathrm{eV})$ : The onset of the neutral fragment signal takes place at around $3.25 \mathrm{eV}$ and it is composed of a single broad peak corresponding to one neutral fragment (Figure 5, left panel), but without contribution from the neutral parent $\mathrm{NpCO}_{2}{ }^{\bullet}$ radical, as shown by the absence of the narrow peak, which indicates that the photodetachment is not the primary process at these photon energies. Then, the neutral fragment 
observed is produced from the photodissociation of the $\mathrm{NpCO}_{2}^{-}$anion, and is the counter fragment of the $\mathrm{Np}^{-}$anion detected when fragmenting in the ion trap. Therefore, the neutral fragment is assigned to the $\mathrm{CO}_{2}$ molecule.

2) Intermediate excitation energies $(3.75-4.59 \mathrm{eV})$ : In this region the signal is quite complex since 3 processes are responsible for the observed shape: the photodissociation channel leading to release of $\mathrm{CO}_{2}$ is still open, the opening of the photodetachment channel leading to the neutral radical $\mathrm{NpCO}_{2}{ }^{\bullet}$ appearing as a new narrow peak component and the DPD channel that leads to the release of two neutral fragments $\mathrm{CO}_{2}$ and $\mathrm{Np}^{\bullet}$.

3) High energy region (> $4.60 \mathrm{eV}$ ): the signal becomes bell-shaped clearly indicating the presence of 2 neutral fragments with quite a lot of kinetic energy and at even higher energies (5.27 eV). The relative intensity of the narrow peak monotonically decreases as compared to that of the broad peak.

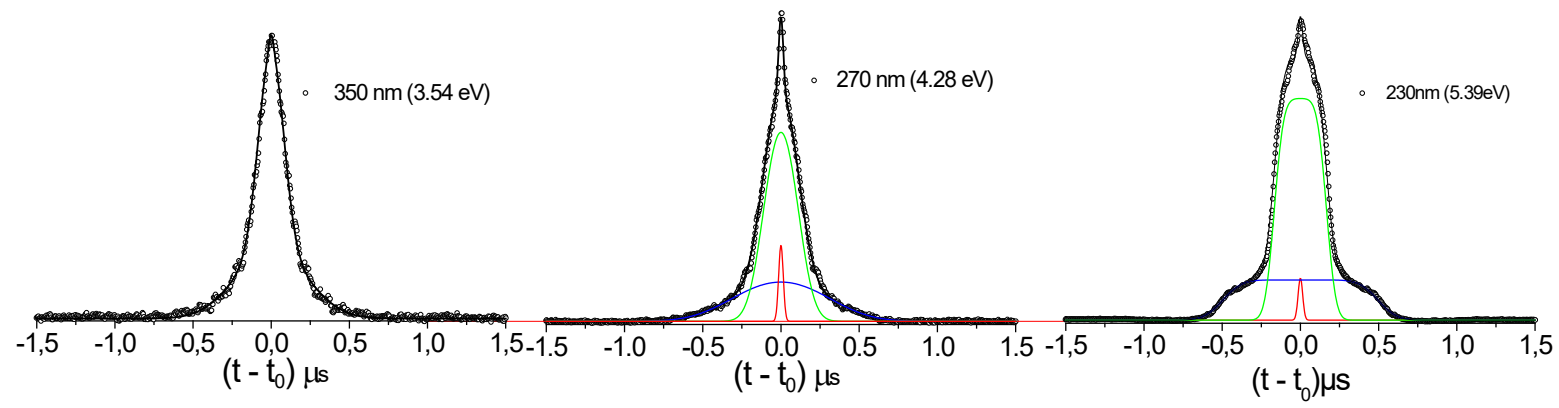

Figure 5: TOF profiles of the neutrals generated from the interaction of the laser with cold $\mathrm{NpCO}_{2}^{-}$anions (40K) in the Gauss tube at different photon energies. Left panel: laser at $350 \mathrm{~nm}(3.54 \mathrm{eV})$ the experimental profile was fitted to a single Lorentzian function corresponding to the $\mathrm{CO}_{2}$ fragment issued from the anion photodissociation. Middle panel: laser at $270 \mathrm{~nm}(4.28 \mathrm{eV})$, both the anion photodissociation and photodetachment channels are competing. Right panel: laser at $230 \mathrm{~nm}$ (5.39 eV), at this energy the anion photodissociation channel is closed, only photodetachment and radical fragmentation are possible. (o) Experimental profile, (-) Gaussian function corresponding to intact $\mathrm{NpCO}_{2}{ }^{\circ}$ radical, (-) step-function corresponding to $\mathrm{Np}^{\circ}$ radical, (-) step-function corresponding to $\mathrm{CO}_{2}$ and (-) total fitting. . The experimental peaks were symmetrized according to the procedure described in the S.I.

The fitting was then performed as the sum of a narrow Gaussian function (accounting for the $\mathrm{NpCO}_{2}{ }^{\bullet}$ component) and two step-functions (accounting for $\mathrm{CO}_{2}$ and $\mathrm{Np} p^{\bullet}$ fragments) with variable widths and slopes. As observed in Figure 5 , the quality of the fitting is reasonable and the relative intensity of the narrow Gaussian component corresponding to the intact $\mathrm{NpCO}_{2}{ }^{\bullet}$ radical is very small 
(or absent) at low excitation energies, increasing at intermediate excitation energies and finally decreasing at the highest excitation energies. The appearance threshold for this component takes place around $3.75-4.00 \mathrm{eV}$.

When comparing the shapes of the signals at all the excitation energies studied (Figure SI-2), a remarkable change in the shape of the peak is observed between 4.59 and $4.96 \mathrm{eV}$ : the component corresponding to the fastest fragment $\left(\mathrm{CO}_{2}\right)$ appears as wings on both sides of the central peak and can be fitted by step functions whose slopes become progressively steeper, which is also the case for the $\mathrm{Np}^{\bullet}$ fragment. This indicates the presence of faster fragments which are produced with repulsive energy release.

At variance with $\mathrm{BzCO}_{2}^{-}$, for which only one fragmentation channel is observed, in the case of $\mathrm{NpCO}_{2}^{-}$two mechanisms are at play: the ionic photodissociation channel of electronically excited $\mathrm{NpCO}_{2}^{-}$anion and the DPD. In the intermediate excitation energy region the $\mathrm{CO}_{2}$ fragment is simultaneously produced by these two different primary processes. Therefore, the integrated area of their corresponding components cannot be used to estimate the fragmentation yield of the $\mathrm{NpCO}_{2}{ }^{\bullet}$ radical as in the case of $\mathrm{BzCO}_{2}{ }^{\circ}$. For the same reason, getting accurate information on the kinetic energy of the fragments is not feasible without a complex simulation and taking into account the internal energy distribution. However, the photodissociation channel becomes negligible at energies above $4.8 \mathrm{eV}$ (Figure 4), therefore, at the highest excitation energy the neutral fragments are only produced from the fragmentation of the internally hot $\mathrm{NpCO}_{2}{ }^{-}$radical and then, the widths of the step-functions can be used to estimate the kinetic energy of the fragments produced from this mechanism.

The maximum kinetic energy of the $\mathrm{Np}^{\bullet}$ and $\mathrm{CO}_{2}$ fragments, obtained from the widths of the step functions of both fragments, gives a relative kinetic energy of $(0.28 \pm 0.02) \mathrm{eV}$ at the excitation energy of $5.39 \mathrm{eV}(230 \mathrm{~nm})$.

In order to shed some light into the photodynamics of these anions, the Vertical and Adiabatic Electron Detachment energies (VDE and ADE, respectively), the adiabatic $S_{n} \leftarrow S_{0}$ electronic transition energies $\left(E_{a d}\right)$ as well as the fragmentation thresholds, were calculated at the DFT and TD-DFT levels 
with the B3LYP functional and the cc-pVTZ basis set. All the results are reported in Table 1 and shown in Figure 6.

Table 1: Electronic transition energies, ADEs, VDEs and different fragmentation energies of the $\mathrm{BzCO}_{2}^{-}$and $\mathrm{NpCO}_{2}^{-}$anions and $\mathrm{BzCO}_{2}{ }^{-}$and $\mathrm{NpCO}_{2}{ }^{\circ}$ radicals, calculated at the DFT and TD-DFT level using the B3LYP functional and the cc-pVTZ basis set.

\begin{tabular}{|c|c|c|}
\hline $\mathrm{ArCO}_{2}^{-}$ & $\begin{array}{c}\mathrm{BzCO}_{2}^{-} \\
(\mathrm{eV})\end{array}$ & $\begin{array}{c}\mathrm{NpCO}_{2}^{-} \\
(\mathrm{eV})\end{array}$ \\
\hline $\mathrm{E}_{\mathrm{ad}}\left(\mathrm{S}_{\mathrm{n}} \leftarrow \mathrm{S}_{0}\right)^{\mathrm{a}}$ & $4.1^{b}$ & $3.2^{b}$ \\
\hline ADE & 3.1 & 3.2 \\
\hline VDE & 3.8 & 3.8 \\
\hline $\begin{aligned} \mathrm{ArCO}_{2}^{-} & \rightarrow \mathrm{Ar}^{-}+\mathrm{CO}_{2} \\
& \rightarrow \mathrm{Ar}+\mathrm{CO}_{2}^{-} \\
& \rightarrow \mathrm{Ar}^{\bullet}+\mathrm{CO}_{2}+\mathrm{e}^{-}\end{aligned}$ & $\begin{array}{l}2.8 \\
4.3 \\
3.3^{c}\end{array}$ & $\begin{array}{l}2.3 \\
4.2 \\
3.2^{c}\end{array}$ \\
\hline $\mathrm{ArCO}_{2}{ }^{\bullet} \rightarrow \mathrm{Ar}^{\bullet}+\mathrm{CO}_{2}$ & 0.2 & 0.0 \\
\hline
\end{tabular}

${ }^{a}$ Lowest excited state with strong oscillator strength. See SI.

${ }^{\mathrm{b}}$ Without $\triangle \mathrm{ZPE}$ correction since it is very small $(0.05 \mathrm{eV})$ as compare to the precision of the calculation.

${ }^{\mathrm{C}}$ The $\mathrm{Bz}^{\bullet}$ electronic affinity is $1.1 \mathrm{eV}$ experimentally, ${ }^{10}$ so that the dissociation channel in $\mathrm{Bz}^{\bullet}+$ $\mathrm{CO}_{2}+\mathrm{e}^{-}$should be at $3.9 \mathrm{eV}$, and similarly the $\mathrm{Np}^{\bullet}$ electron affinity being $1.4 \mathrm{eV}$ experimentally, ${ }^{26}$ the dissociation channel $\mathrm{Np}{ }^{\circ}+\mathrm{CO}_{2}+\mathrm{e}^{-}$should be at $3.7 \mathrm{eV}, 1.4 \mathrm{eV}$ above the $\mathrm{Np}^{-}+\mathrm{CO}_{2}$ channel.

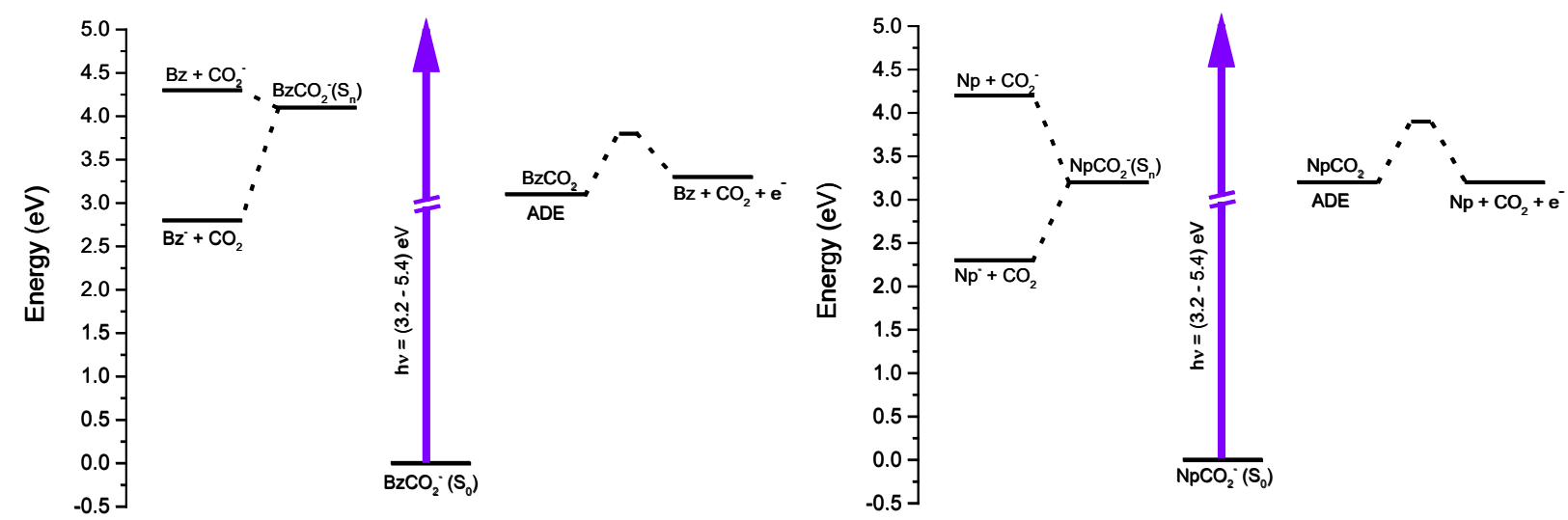

Figure 6: Energy diagram for the DPD and photodissociation processes of $\mathrm{BzCO}_{2}^{-}$(left panel) and $\mathrm{NpCO}_{2}^{-}$(right panel). The DPD and photodissociation are shown on the right and left part of each panel, respectively. The values were obtained from Table 1. The energy barriers for the DPD processes are estimated in the Discussion section. In both anions the excitation energy was varied from $3.2 \mathrm{eV}$ to $5.4 \mathrm{eV}$. 


\section{Discussion}

The experimental results clearly show that the primary photoinduced processes are different for $\mathrm{BzCO}_{2}^{-}$and $\mathrm{NpCO}_{2}^{-}$, so the results will be discussed separately.

\section{Benzoate:}

The primary process is the photodetachment to produce the $\mathrm{BzCO}_{2}{ }^{\circ}$ radical followed by its fragmentation in $\mathrm{Bz}^{\bullet}$ and $\mathrm{CO}_{2}$. This process becomes more important as the excitation energy increases since the internal energy of the $\mathrm{BzCO}_{2}{ }^{\bullet}$ radical also increases. This behavior has already been observed in the simpler acetyloxyl anion $\mathrm{CH}_{3} \mathrm{CO}_{2}{ }^{-}$that dissociates after photodetachment. ${ }^{3}$

The signal corresponding to the $\mathrm{BzCO}_{2}{ }^{\bullet}$ radical becomes detectable at excitation energies $\geq 3.88 \mathrm{eV}$, in good agreement with the calculated VDE (3.8 $\mathrm{eV})$. The large difference between the calculated VDE (3.8 eV) and ADE (3.1 $\mathrm{eV})$ suggests a large geometry difference between the anion and the radical, therefore very low Franck-Condon factors are expected for the adiabatic process.

The dissociation energy of $\mathrm{BzCO}_{2}{ }^{\bullet}$ in $\mathrm{CO}_{2}$ and $\mathrm{Bz}^{\bullet}$ was calculated in this work at the DFT (B3LYP/cc-pVTZ) level to be only $0.2 \mathrm{eV}$ including $\triangle Z P E$ (Table 1). Thus, the observation of undissociated $\mathrm{BzCO}_{2}{ }^{\bullet}$ radical at excitation energies $\geq 3.88 \mathrm{eV}$, which is $0.8 \mathrm{eV}$ of excess energy above the $A D E$, implies that there is a barrier for the dissociation process.

The photodetachment threshold is not well defined and the photodetachment efficiency increases slowly as the photon energy increases (Figure 3$).{ }^{8}$ At the lowest energy $(3.88 \mathrm{eV})$ at which significant signal was obtained, the fragmentation yield is already quite high (45 $\pm 10 \%)$. This indicates that at this energy, $45 \%$ of the molecules have an internal energy larger than the dissociation barrier and $55 \%$ have an internal energy lower than the barrier. The internal energy distribution imparted to the radical can be obtained from the electron binding energy measured by Woo et al. ${ }^{8}$ By integrating the experimental electron binding energy from $0.0 \mathrm{eV}$ to this lowest energy of $3.88 \mathrm{eV}$, one can find the energy at which the population is split in a 
ratio $45 / 55$. The dissociation threshold is then obtained at $(3.80 \pm 0.02) \mathrm{eV}$ (see Figure 3 and Figure SI-3).

The dissociation energy barrier depends on the ADE of the benzoate anion, which is reported in previous studies between $3.59 \mathrm{eV}$ experimentally ${ }^{8}$ and $3.33-3.44 \mathrm{eV}$ theoretically. ${ }^{8,9}$ Due to this discrepancy, the ADE value calculated in this work at the DFT/B3LYP/cc-pVTZ level $(3.1 \mathrm{eV})$ was used in order to be able to compare with naphthoate anion for which the experimental $A D E$ is not reported in the literature. Then, considering the calculated ADE (3.1 $\mathrm{eV}$ ) and the fact that the DPD channel opens at $3.80 \mathrm{eV}$, this leads to a barrier of $0.7 \mathrm{eV}$, which is larger than the barrier for dissociation of the acetyloxyl radical $(0.2 \mathrm{eV}){ }^{4}$

\section{Naphtoate}

The onset for the photodissociation of this anion takes place at around $3.25 \mathrm{eV}$ in good agreement with the calculated adiabatic transition energy of 3.2 $\mathrm{eV}$ for the lowest excited electronic state with strong oscillator strength as shown in Table SI-1. Then, at low excitation energies the primary process is suggested to be the electronic excitation of $\mathrm{NpCO}_{2}^{-}$followed by the photodissociation to the lowest energy channel producing $\mathrm{Np}^{-}$and $\mathrm{CO}_{2}$ (the calculated energy threshold for this channel is $2.3 \mathrm{eV}$ ). Both fragments were observed experimentally in different experiments: the $\mathrm{Np}^{-}$anion was observed from the excitation in the trap and the neutral $\mathrm{CO}_{2}$ from the excitation of the fast ions in the "Gauss" tube.

The experimental electron detachment energy of the $\mathrm{Np}^{-}$anion is 1.4 $\mathrm{eV},{ }^{26}$ consequently at the fragments appearance threshold $(3.25 \mathrm{eV})$, the excess energy $(0.95 \mathrm{eV})$ is not enough to produce the electron detachment of the $\mathrm{Np}^{-}$anion.

The ADE of $\mathrm{NpCO}_{2}^{-}$is calculated at $3.2 \mathrm{eV}$, however the photodetachment is not competitive with the photodissociation at this excitation energy $(3.25 \mathrm{eV})$ since the Franck-Condon factors in the vicinity of the adiabatic transition are expected to be negligible as inferred from the large difference between the ADE and the VDE $(3.8 \mathrm{eV})$.

At excitation energies closer to the VDE, the photodetachment starts to compete with the photodissociation. The experimental threshold for the onset of 
the neutral $\mathrm{NpCO}_{2}{ }^{\bullet}$ is $3.75 \mathrm{eV}$, in good agreement with the calculated VDE of $3.8 \mathrm{eV}$.

A fraction of the $\mathrm{NpCO}_{2}{ }^{\bullet}$ radicals may undergo decarboxylation to produce $\mathrm{Np}^{\bullet}$ and $\mathrm{CO}_{2}$ through an energy barrier as in the case of $\mathrm{BzCO}_{2}{ }^{\bullet}$. However, in this case the analysis of the experimental data is not as straightforward as in the latter case, since the two fragmentation channels (ionic and neutral) are competing to produce the same neutral fragments.

At the highest excitation energies, above $4.6 \mathrm{eV}$, the ionic fragmentation channel is closed as observed from the $\mathrm{Np}^{-}$signal (Figure 4) and from the change of the shape of the neutral fragments signal (Figure SI-2). In addition, the width of the distribution is barely sensitive to the excitation energy. This suggests that the dissociation dynamics is mediated by a substantial exit barrier.

In the case of $\mathrm{NpCO}_{2}^{-}$, the photoelectron spectrum is unknown so that the barrier for the fragmentation of the $\mathrm{NpCO}_{2}{ }^{\bullet}$ radical cannot be estimated from experimental data as in the case of $\mathrm{BzCO}_{2}^{-}$. However, some estimation of the barrier can be obtained from the comparison of the kinetic energy of the $\mathrm{CO}_{2}$ fragment in both systems at 230nm.

In the results section it was reported that the relative kinetic energy of the fragments at $5.39 \mathrm{eV}$ of excitation energy is $(0.32 \pm 0.04) \mathrm{eV}$ and $(0.28 \pm 0.02)$ eV for $\mathrm{BzCO}_{2}{ }^{-}$and $\mathrm{NpCO}_{2}{ }^{-}$, respectively. Therefore, very similar energy barriers $(0.7 \mathrm{eV})$ are expected in both cases.

The kinetic energies measured at $5.39 \mathrm{eV}$ for $\mathrm{BzCO}_{2}{ }^{\bullet}(0.32 \pm 0.04) \mathrm{eV}$ and $\mathrm{NpCO}_{2}{ }^{\bullet}(0.28 \pm 0.02) \mathrm{eV}$, represent $15 \%$ and $13 \%$ of the maximum available energy $\mathrm{E}_{\mathrm{avl}}=2.09 \mathrm{eV}\left(\mathrm{BzCO}_{2}{ }^{\circ}\right)$ and $2.19 \mathrm{eV}\left(\mathrm{NpCO}_{2}{ }^{\circ}\right)$. According to the impulsive model ${ }^{27}$ used by $Z$. Lu et al. $^{3}$ for the acetyloxy radical dissociation, the translational energy release is given by $E_{T}=E_{a v l}{ }^{*}\left(\mu_{\alpha \beta} \mu_{A B}\right)$, with $\mu_{A B}$ being the reduced mass of the two fragments (28 for $\mathrm{BzCO}_{2}{ }^{\bullet}$ and 32.7 for $\mathrm{NpCO}_{2}{ }^{\bullet}$ ) and $\mu_{\alpha \beta}=6$ the reduced mass of the recoiling atoms involved in the dissociated bond $\mathrm{C}-\mathrm{C} .{ }^{27}$ Then, the calculated $\mathrm{E}_{\mathrm{T}}$ are $0.45 \mathrm{eV}\left(21 \% \mathrm{E}_{\mathrm{avl}}\right)$ and $0.40 \mathrm{eV}(18 \%$ $\mathrm{E}_{\mathrm{avl}}$ ), for $\mathrm{BzCO}_{2}{ }^{\bullet}$ and $\mathrm{NpCO}_{2}{ }^{\bullet}$, respectively.

The dissociation energy barriers for both radicals were calculated at the DFT and TD-DFT/CAM-B3LYP/cc-pVDZ level. The calculated values for 
$\mathrm{BzCO}_{2}{ }^{\bullet}$ and $\mathrm{NpCO}_{2}{ }^{\bullet}$ are $0.52 \mathrm{eV}$ and $0.53 \mathrm{eV}$, respectively, in reasonable agreement with the corresponding experimental value of $0.7 \mathrm{eV}$.

As shown in Figure 7, the barriers in both radicals are developed as a consequence of the crossing between the corresponding ground and second doublet excited states.

As previously mentioned, the calculated energy barriers for the decarboxylation of these aromatic radicals $(0.52 \mathrm{eV}$ and $0.53 \mathrm{eV})$ are around $0.3 \mathrm{eV}$ larger than the energy barrier $(0.2 \mathrm{eV})$ for the decarboxylation of the $\mathrm{CH}_{3} \mathrm{CO}_{2}$ aliphatic radical. ${ }^{4}$ In the aromatic radicals the $\pi$ orbital on the $\mathrm{CO}_{2}$ group is conjugated with the $\pi$ orbital of the aromatic ring. As shown in Figure $\mathrm{SI}-4$, the $\mathrm{C}-\mathrm{CO}_{2}$ bond stretching along the MPE is accompanied by the OCO angle opening reducing the $\mathrm{sp}^{2}$ character of the $\mathrm{C}$ atom in the $\mathrm{CO}_{2}$ group to increase its $\mathrm{sp}$ character as needed by the $\mathrm{CO}_{2}$ fragment. This change partially breaks the conjugation of the $\mathrm{CO}_{2} \pi$ electrons with the aromatic ring and then it requires extra energy to reach the transition state (TS).

To reach the TS geometry the $\mathrm{C}-\mathrm{CO}_{2}$ bond distance has to be elongated by $0.46 \AA$ and the OCO has to increase $41^{\circ}$ from their corresponding values at the equilibrium geometry of the radical. At the very beginning of the MEP (blue vertical line in Figure SI-4) the $\mathrm{C}-\mathrm{CO}_{2}$ distance increases $0.04 \AA$ and the OCO angle increases $16^{\circ}$, while the energy is already $0.22 \mathrm{eV}$. These values represent $9 \%, 39 \%$ and $41 \%$ of the change required by the $\mathrm{C}-\mathrm{CO}_{2}$ distance, the OCO angle and the energy, respectively, to reach the TS. This means that most of this energy $(0.22 \mathrm{eV})$ is invested to open de OCO angle and partially breaking the $\pi$ conjugation. Thus, it can explain the lower energy barrier determined for the $-\mathrm{CO}_{2}$ bond breaking in the $\mathrm{CH}_{3} \mathrm{CO}_{2}$ radical, in which, the conjugation breaking does not takes place.

The main difference observed between $\mathrm{BzCO}_{2}^{-}$and $\mathrm{NpCO}_{2}^{-}$is the absence of the ionic fragmentation channel at low excitation energies in the case of the former anion. 

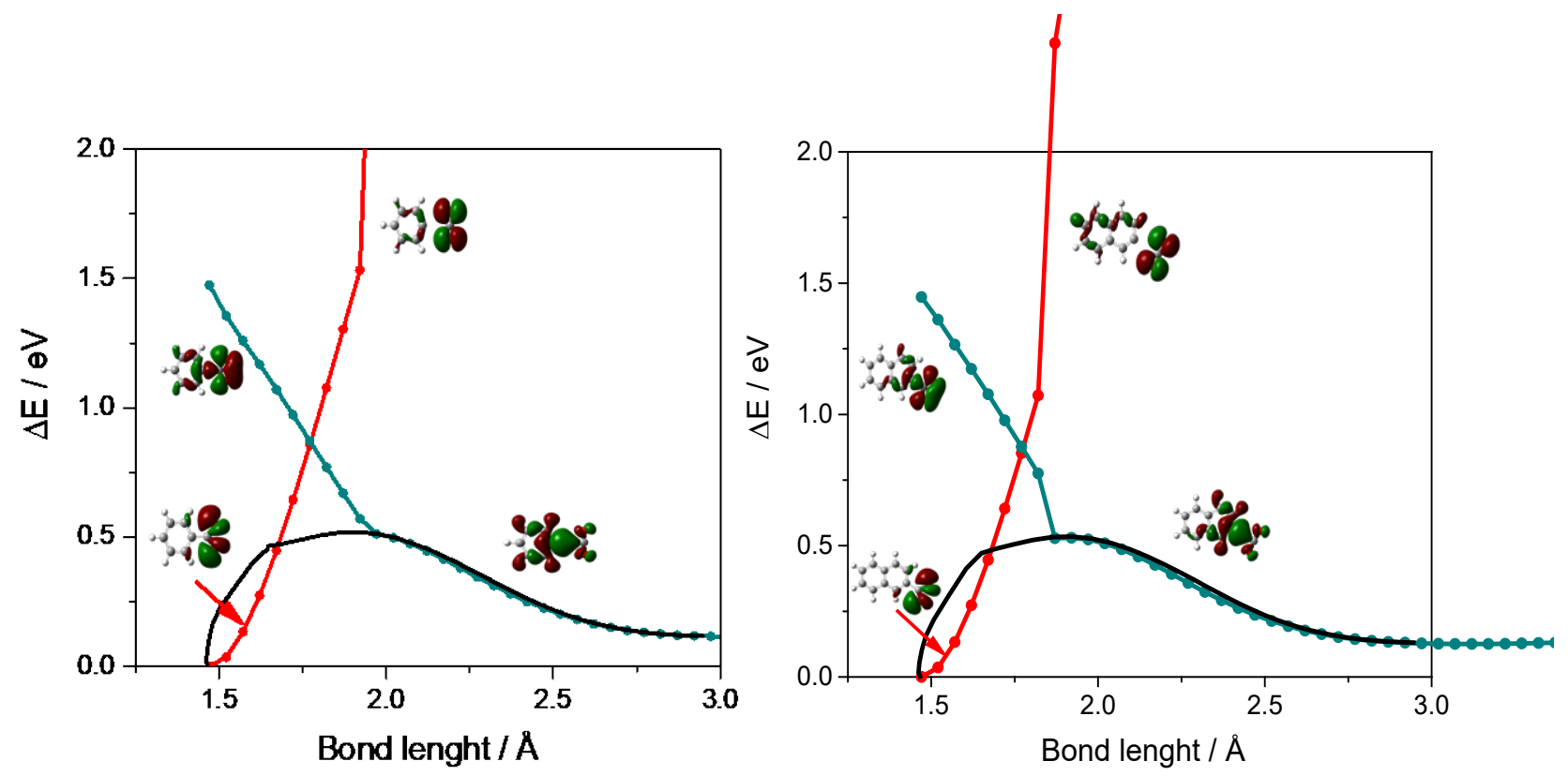

Figure 7: Potential energy function for the electronic ground state (red) and second excited electronic state (green) as a function of the $\mathrm{C}-\mathrm{CO}_{2}$ distance for the $\mathrm{BzCO}_{2}{ }^{\bullet}$ (left) and $\mathrm{NpCO}_{2}{ }^{-}$(right) radicals. The SOMO of both states at both sides of the curve crossing are also shown. The black lines correspond to the corresponding energy barriers obtained from MEP calculations.

In the case of $\mathrm{NpCO}_{2}^{-}$the origin of the lowest electronic transition with strong oscillator strength is at the same energy as the ADE and $0.6 \mathrm{eV}$ below the VDE at which the photodetachment is actually observed. Therefore, at low excitation energies the ionic fragmentation of $\mathrm{NpCO}_{2}^{-}$anion is the only process at play. According to calculations, the lowest excited state with strong oscillator strength in $\mathrm{BzCO}_{2}{ }^{-}$lies at $4.1 \mathrm{eV}$, which is $1.0 \mathrm{eV}$ above the $\mathrm{ADE}$ and at the same energy than the VDE. The onset for the photodetachment is observed between both the ADE and VDE and since the photodetachment is expected to be faster than the bond dissociation, the anion fragmentation is unlikely to be competitive with the photodetachment, in agreement with the fact that we have not been able to detect the $\mathrm{Bz}^{-}$anion in our experimental setup.

\section{Conclusions}

The photoinduced processes in $\mathrm{BzCO}_{2}{ }^{-}$and $\mathrm{NpCO}_{2}{ }^{-}$anions were studied by means of photofragmentation spectroscopy of cold ions, detecting neutral and ionic fragments.

The photodetachment process followed by decarboxylation of the internally hot $\mathrm{BzCO}_{2}{ }^{\bullet}$ and $\mathrm{NpCO}_{2}{ }^{\bullet}$ radicals through an exit barrier is common to both anions as also reported in previous work for $\mathrm{CH}_{3} \mathrm{CO}_{2}{ }^{-3}$. 
From the knowledge of the binding energy of the electron in $\mathrm{BzCO}_{2}^{-}$ obtained through photoelectron measurements ${ }^{8}$ and the observation of stable and unstable radicals, the energy of the exit barrier for the dissociation process of this radical was determined to be $(0.7 \mathrm{eV})$. The barrier for $\mathrm{NpCO}_{2}{ }^{\bullet}$ has been estimated to be the same as for $\mathrm{BzCO}_{2}{ }^{\circ}$, within the experimental error, by comparison of the total kinetic energy of the fragments in both radicals.

At variance with $\mathrm{CH}_{3} \mathrm{CO}_{2}^{-}$and $\mathrm{BzCO}_{2}^{-}$, in the case of $\mathrm{NpCO}_{2}^{-}$a new ionic fragmentation channel producing $\mathrm{Np}^{-}$and $\mathrm{CO}_{2}$ is open at low excitation energy. This process arises from the primary electronic excitation of the $\mathrm{NpCO}_{2}^{-}$anion likely followed by IC to the $\mathrm{S}_{0}$ state and subsequent dissociation. The fact that this channel is only observed in $\mathrm{NpCO}_{2}^{-}$is a consequence of the lower energy of the first optically active excited state of this anion as compared to the others due to a larger stabilization by resonance.

The photodetachment of $\mathrm{ArCO}_{2}^{-}$followed by decarboxylation has been used for a long time to produce the corresponding aryl radicals, used as nucleophiles in organic chemist synthesis. Up to now the ionic fragmentation channel producing $\mathrm{Ar}^{-}$anions has always been dismissed. However, since the reactivity of the $\mathrm{Ar}^{-}$anion is different to that of the $\mathrm{Ar}^{\bullet}$ radicals, they have to be taken into account especially for large aromatic groups.

\section{Acknowledgments}

This work has been conducted within the International Associated Laboratory LEMIR (CNRS/CONICET) and wassupported by CONICET, FONCyT, SeCyTUNC and the ANR Research Grant (ANR2010BLANC040501-ESPEM). We also acknowledge the use of the computing facility cluster Méso-LUM of the LUMAT federation (LUMAT FR 2764). 


\section{References}

1 R. B. Metz, A. Weaver, S. E. Bradforth, T. N. Kitsopoulos and D. M. Neumark, J. Phys. Chem., 1990, 94, 1377-1388.

2 R. E. Continetti and H. Guo, Chem. Soc. Rev., 2017, 46, 7650-7667.

3 Z. Lu and R. E. Continetti, J. Phys. Chem. A, 2004, 108, 9962-9969.

4 Y. Z. Zhou, S. Li, Q. S. Li and S. W. Zhang, J. Mol. Struct. THEOCHEM, 2008, 854, 40-45.

$5 \quad$ M. W. Forbes and R. A. Jockusch, J. Am. Chem. Soc., 2009, 131, 1703817039.

$6 \quad$ M. W. Forbes, A. M. Nagy and R. A. Jockusch, Int. J. Mass Spectrom., 2011, 308, 155-166.

7 S. B. Nielsen, A. Lapierre, J. U. Andersen, U. V Pedersen, S. Tomita and L. H. Andersen, Phys. Rev. Lett. 2001, 87, 228102.

8 H. K. Woo, X. Bin Wang, B. Kiran and L. S. Wang, J. Phys. Chem. A, 2005, 109, 11395-11400.

9 J. D. Steill and J. Oomens, J. Phys. Chem. A, 2009, 113, 4941-4946.

10 R. F. Gunion, M. K. Gilles, M. L. Polak and W.C. Lineberger,Int. J. Mass Spectrom. Ion Proc., 1992, 117, 601-620.

11 M. H. Stockett, M. Boesen, J. Houmøller and S. Brøndsted Nielsen, Angew. Chemie - Int. Ed., 2017, 56, 3490-3495.

12 I. B. Nielsen, S. Boyé-Péronne, M. O. a El Ghazaly, M. B. Kristensen, S. Brøndsted Nielsen and L. H. Andersen, Biophys. J., 2005, 89, 2597-604.

13 B. Lucas, M. Barat, J. A. Fayeton, M. Perot, C. Jouvet, G. Grégoire and S. Brøndsted Nielsen, J. Chem. Phys., 2008, 128, 164302.

14 K. A. Hanold, C. R. Sherwood and R. E. Continetti, J. Chem. Phys., 1995, 103, 9876-9879.

15 B. L. J. Poad, A. W. Ray and R. E. Continetti, J. Phys. Chem. A, 2013, 117, 12035-12041.

16 A. Faulhaber, D. Szpunar, K. Kautzman and D. M. Neumark, J. Phys. Chem. A, 2005, 109, 10239-10248.

17 S. Sunil Kumar, M. Pérot-Taillandier, B. Lucas, S. Soorkia, M. Barat and J. A. Fayeton, J. Phys. Chem. A, 2011, 115, 10383-10390.

18 I. Alata, J. Bert, M. Broquier, C. Dedonder, G. Feraud, G. Grégoire, S. Soorkia, E. Marceca, C. Jouvet, E. Marceca and C. Jouvet, J. Phys. Chem. A, 2013, 117, 4420-7.

19 G. Féraud, C. Dedonder, C. Jouvet, Y. Inokuchi, T. Haino, R. Sekiya and T. Ebata, J. Phys. Chem. Lett., 2014, 5, 1236-1240.

20 M. Berdakin, G. Féraud, C. Dedonder-Lardeux, C. Jouvet and G. A. Pino, Phys. Chem. Chem. Phys., 2014, 16, 10643-10650.

21 N. Esteves-López, C. Dedonder-Lardeux, C. Jouvet, J. Chem. Phys. 2015, 143, 074303.

22 W. C. Wiley and I. . McLaren, Rev. Sci. Instrum., 1955, 26, 1150.

23 TURBOMOLE V6-6 2011, a development of University ofKarlsruhe and Forschungszentrum Karlsruhe $\mathrm{GmbH}, 1989-2007$, TURBOMOLE GmbH, since 2007; available fromhttp://www.turbomole.com.

24 D. E. . Woon and T. H. Dunning Jr., J. Chem. Phys., 1993, 98, 13581371.

25 M. J. Frisch, G. W. Trucks, H. B. Schlegel, G. E. Scuseria, M. A. Robb, J. R. Cheeseman, G. Scalmani, V. Barone, B. Mennucci, G. A. Petersson, H. Nakatsuji, M. Caricato, X. Li, H. P. Hratchian, A. F. Izmaylov, J. Bloino, 
G. Zheng, J. L. Sonnenberg, M. Hada, M. Ehara, K. Toyota, R. Fukuda, J. Hasegawa, M. Ishida, T. Nakajima, Y. Honda, O. Kitao, H. Nakai, T. Vreven, J. A. M. Jr., J. E. Peralta, F. Ogliaro, M. Bearpark, J. J. Heyd, E. Brothers, K. N. Kudin, V. N. Staroverov, R. Kobayashi, J. Normand, K. Raghavachari, A. Rendell, J. C. Burant, S. S. lyengar, J. Tomasi, M. Cossi, N. Rega, J. M. Millam, M. Klene, J. E. Knox, J. B. Cross, V. Bakken, C. Adamo, J. Jaramillo, R. Gomperts, R. E. Stratmann, O. Yazyev, A. J. Austin, R. Cammi, C. Pomelli, J. W. Ochterski, R. L. Martin, K. Morokuma, V. G. Zakrzewski, G. A. Voth, P. Salvador, J. J. Dannenberg, S. Dapprich, A. D. Daniels, Ö. Farkas, J. B. Foresman, J. V. Ortiz, J. Cioslowski and D. J. Fox, Gaussian09 (Revision D.01), Gaussian Inc. Wallingford, CT. 2009.

26 K. M. Ervin, T. M. Ramond, G. E. Davico, R. L. Schwartz, S. M. Casey and W. C. Lineberger, J. Phys. Chem. A, 2001, 105, 10822-10831.

27 K. A. Trentelman, S. H. Kable, D. B. Moss and P. L. Houston, J. Chem. Phys., 1989, 91, 7498. 